International Journal of Child, Youth and Family Studies (2015) 6(4.1): 689-708

\title{
LIVING IN A TRANSNATIONAL ROOM: TRANSNATIONAL ONLINE COMMUNICATION BY UNACCOMPANIED KOREAN ADOLESCENTS IN THE UNITED STATES
}

\section{Tae-Sik Kim}

\begin{abstract}
Seeking to understand the wide use of the Internet as a transnational communications technology, this qualitative study inquired into the Internet use of unaccompanied Korean adolescents. Grounded in the findings of the adolescents' living contexts, this study set a basic question: How do the transnational online communication practices of unaccompanied adolescents shape and reflect their transnational lives? Spending a tremendous amount of time in their rooms at host homes due to their limited social relationships in the United States, they intensively consumed Korean media content via the Internet. They also made efforts to maintain interpersonal relationships with people in Korea by utilizing multiple online technologies. This study found that technological availability, cultural sensibility, and healthy peer community were important contexts of the adolescents' transnational online communication.
\end{abstract}

Keywords: transnational online communication, unaccompanied adolescents, internet use, media consumption, interpersonal communication

Tae-Sik Kim is a Lecturer/ Postdoctoral Fellow in the Department of Media Studies and Journalism at Masaryk University, Joštova 10, 602 00, Brno, Czech Republic. E-mail: beinkid@mail.muni.cz 
International Journal of Child, Youth and Family Studies (2015) 6(4.1): 689-708

The present study is a part of a larger research project on unaccompanied Korean adolescents in the United States, and examines, in particular, the young international students' transnational media consumption and communication. The study is grounded in an understanding of two important aspects of the study population: as young expatriates pursuing precollege education in a foreign country, they belong to the wave of "early study abroad" (Ahn, 2011; Popadiuk, 2010); and as “digital natives”, they adroitly adopt advanced communication technologies in their everyday lives (Palfrey \& Gasser, 2008).

International education is a typical way of accumulating sociocultural capital in a globalized world (Ong, 1999). This transnational activity reflects multilayered relationships between and beyond the sending and receiving countries: the global hegemonic relationship among nation-states has led to large-scale migrations to some English-speaking countries for the purpose of education. As a result, an increased number of actors are seeking their economic fortunes in commercialized international education, and well-to-do international students and their families are able to engage in transnational lives more easily than before (Collins, 2009). The present study population, comprising unaccompanied Korean adolescents in the United States, is a typical example of the recent wave of educational migration, which has been accelerated by increasing competition not only in the field of education but also in society as a whole. While rapid economic development has increased the number of middle-class families who can afford to invest a large amount of money in their children's education, the influence of neoliberal ideas on norms in Korea has forced families to look for more advantageous positions in endless competition. Since the late 1990s, the number of Korean precollege students abroad has increased, creating a social phenomenon known as educational exodus (Kang \& Abelmann, 2011).

The recent increase in transnationalism has been accompanied by a rapid increase in the availability and affordability of international telephone services (Vertovec, 2004). Rapid development of new communications technologies and more efficient means of transport have facilitated transnational life: individuals who relocate are able to be engaged in multiple locales. Although transnational communication is not new, its scope among young people who have grown up in a more digitally-networked world has widened dramatically. Young Koreans are viewed as aggressive users of new communications technologies; they are often called "cyber kids” (Yoon, 2006). In investigating its geographically flexible and technologically adaptive participants, the present study focuses particularly on how unaccompanied Korean adolescents use communications technologies, and how they contextualize their communication practices within other aspects of their transnational experiences.

The study begins with a discussion of the contexts of the unaccompanied adolescents' lives. Young international Korean students routinely experience unstable personal relationships, cultural estrangement, social isolation, and idealization of their past experiences in Korea (Kim, 2014). These experiences furnish important clues for comprehending the ways in which such students have adopted advanced communications technologies to facilitate their transnational communication practices. Therefore, the present article offers a summary of the life experiences of the study population, then shows how these students actively embrace the Internet and other technologies to maintain and develop communities between Korea and the United States. 
International Journal of Child, Youth and Family Studies (2015) 6(4.1): 689-708

\section{Literature Review and Study Background}

\section{Unaccompanied Adolescents}

Unaccompanied Korean adolescents who go abroad to study are called jogi yuhaksaeng, a neologism meaning “early study abroad students.” The modern trend of pursuing international education can be traced to the notions of cultural citizenship and neoliberal economic citizenship (Miller, 2007). International education is a consequence of neoliberalism; it is an aspect of the pursuit of the accumulation of sociocultural capital, which is believed to foster political and economic success (Ong, 1999). The tradition of intense competition in Korean education gives further impetus to this phenomenon. Lavish spending on private supplemental education in Korea is not unusual (Park, Byun, \& Kim, 2011), and about 70\% of precollege students participate in after-school private education (Korean Statistical Information Service, 2012). The ever-intensifying educational competition in Korea within the global neoliberal context has fostered a trend of sending young Korean students to English-speaking countries to pursue and secure advantageous positions (Kang, 2013; Park \& Abelmann, 2004). Recognizing the perceived value of English-language skills, the education industry and well-to-do families have reacted swiftly (Park, 2009).

The purpose of studying abroad is not only to learn English, but also to pursue degrees from renowned colleges in English-speaking countries, which are widely believed among Koreans to maximize human capital accumulation (Shin, 2013). This belief is fact-based: 65.3\% of high-ranking bureaucrats in the current Korean government have foreign degrees, and 75\% of them have studied in the United States (Ryu, 2008). Another important attraction of early study abroad is that the educational environment in many foreign countries is less competitive than it is in Korea (Koo, 2007). Although the total number of precollege students has slowly decreased, there were still 18,742 Korean precollege students enrolled in schools abroad in 2012 (Korean Educational Development Institute, 2012).No statistical report covering the number of Korean precollege students by country has been published, but it is estimated that about $30 \%$ of Korean international students in the United States are precollege students (Kim, 2005).

Studies have been conducted on Korean international students in various countries, such as Canada (e.g., Shin, 2013), Singapore (e.g., Kang, 2013), and the United Kingdom (Moon, 2011). However, these studies have not focused on the use of communications media; in some, the subjects include both accompanied and unaccompanied adolescents. Some studies have shown that unaccompanied students may have especial difficulty in building cultural competency in the host society; eventually this may result in an increasing attachment to their homeland and culture (e.g., Ying, 2001). Others have also pointed out that unaccompanied sojourners suffer high acculturative stress as well as homesickness in host countries (Kuo \& Roysircar, 2006; Tartakovsky, 2007). Although there have been multiple comprehensive studies on the cultural experiences of unaccompanied precollege students (e.g., Popadiuk, 2010), there has been little specific attention to one important aspect of their life experiences in foreign countries: their use of electronic communications media.

\section{Transnational Media Use and Communication}

With the emergence of advanced communications technologies, such as the Internet and mobile phones, migrants are able to routinely communicate with family members and friends 
across national borders, leading to dramatic changes in their everyday lives (e.g., Bacigalupe \& Camara, 2012). migrants can now access "the density, realtime character, and flexibility” of communication that these technologies make possible, and which were not available to their predecessors (Portes, 2001, p. 188).

How transnational family relationships are maintained or transformed by technologically mediated communication is the most popular topic in transnational communications research (e.g., Kang, 2012). Advanced communications technologies play an important role in maintaining existing family practices (Wilding, 2006). The Internet has been widely adopted by migrant families to maintain healthy relationships with communities in their home countries (Bacigalupe \& Camara, 2012). There are also studies on wider aspects of interpersonal communication, including peer and community relationships maintained by migrants using advanced communications technologies. Metyková (2010) states that technologically competent migrants flexibly adopt a variety of interpersonal communications technologies, including video conferencing and multimedia-sharing applications, while Collins (2009) focuses more specifically on the uses of social-networking sites by sojourner students in maintaining and developing transnational friendships.

As noted in various studies on the relationships between mass media and immigrants' daily lives, many people who live outside their home countries still actively consume mass media content produced at home (e.g., Christiansen, 2004; Mayer, 2003; Sun, 2005), online home-country media (Yin, 2013), or ethnic media in the host countries (e.g., Lin, Song, \& BallRokeach, 2010). According to Metyková (2010), young migrants who are accustomed to Internet technology tend to maintain the patterns of media consumption they formed in their countries of origin. While studies on interpersonal communications in transnational settings pay more attention to relationship maintenance and psychological consequences, those on transnational media use tend to stress the influences of media on identity formation, questioning whether migrated subjects maintain their ethnic identities or acculturate to their new communities (e.g., Wang \& Quan, 2013). Also, psychological factors that are part of the process of acculturation, such as acculturative stress and homesickness, have been analyzed to find their relationships with patterns of media use (e.g., Ye, 2005). Although these studies provide important empirical evidence of how certain communication practices are correlated with cultural consequences of transnational life, they do not pay extensive attention to the context of everyday life surrounding the transnational communication practices and activities in question.

Wilding and Metyková, on the contrary, stress the importance of contextual understandings of migrants' daily lives in studying transnational communication practices; Wilding (2006, p. 127) posits questions such as, "When, under what circumstances, and why, do people decide to adopt the Internet as a communications technology?”. Similarly, Metyková (2010, p. 326) places "migrants' media use in the context of their everyday lived experiences and routines.” As a part of a larger study on life experiences of unaccompanied Korean adolescents in the United States, this study also places the young migrants' media use and mediated communications in the broader context of their life experiences. Understanding that media use is one of the most important parts of transnational life, this study particularly looks at how media use and mediated communications shape young sojourners' transnational lives as well as reflect their life experiences overseas. 
International Journal of Child, Youth and Family Studies (2015) 6(4.1): 689-708

\section{Unaccompanied Korean Adolescents in the United States}

This study is the second part of my dissertation research focusing on the transnational communications and the cultural positioning of unaccompanied Korean adolescents. In order to find the contextual background of their communication practices, I first investigated the young sojourners' life experiences in the United Sates (Kim, 2014). Therefore, the research questions driven by this study are grounded in an understanding of their life experiences, which are summarized in the following sections.

\section{The Unaccompanied}

Being separated from parents was the most distinctive living context of the unaccompanied adolescents. All participants in this study lived with host families, relatives, or their parents' friends in the United States. The double foreignness experienced as a result of living with others in a foreign country hindered them in building stable personal relationships. First, they commonly suffered as a result of their incompetence with the language and culture in their host homes, avoiding intimate interactions with host-family members. Second, a host home was not necessarily a permanent base. Rather, many participants underwent frequent moves to new host homes for a variety of reasons, including a host's poor service, emotional conflict with household members, and business relationships with study-abroad agents.

The young students tended not to form social relationships easily within their same-age peer group. Most participants reported that they had comparatively few interethnic friends, and that activities with those friends were limited. Along with the language barrier, a different peer culture was cited as the main cause of unsatisfying personal relationships with American classmates. On the other hand, the relatively small number of Korean students in American schools also created complications regarding peer relationships among the adolescents; they became extremely cautious in their maintenance of personal relationships with fellow Koreans.

\section{Young Strangers}

Many participants encountered difficulties in negotiating foreign customs, cultures, and systems in their everyday lives. First, the unaccompanied adolescents often became business targets of the early study abroad industry. Their lack of knowledge about American schools, cities, and environments forced them to rely strongly on professional agencies. Although they had a good understanding of their business relationships with the agencies, host families, and schools, they often thought of the relationships negatively because they felt they had become targets for profit-seeking, particularly by professional agencies. For the adolescents who had little experience in the business world, relationships with adults occasionally became very stressful, discouraging them from placing trust in adults generally.

Participants often pointed out that American school cultures and systems were the main barriers separating them from school communities. In Korea, students usually take the same subjects with the same classmates throughout the school year. Many students thought that the Korean system was more advantageous than the American system in terms of the opportunity to establish friendships. As transfer students, they also experienced hardships entering into group activities, especially in contexts where existing groups with strong identities had long been established. At the same time, they intentionally disengaged themselves from activities. Many 
International Journal of Child, Youth and Family Studies (2015) 6(4.1): 689-708

students in this study tended to regard their high-school education in the United States as merely a course they needed to pass to fulfil the purpose of early study abroad: entering an American college. The different after-school culture in the United States was another challenge; more than a third of the participants disliked having free time after school and complained about the disorganization of their everyday lives. Their schedule in Korea, which was filled with private after-school classes, was organized mainly by their parents and counsellors from private institutes. For these passive adolescents, time management after school in the United States was a big challenge.

Last but not least, restricted mobility brought about by limited transport options was an important stressor for the unaccompanied adolescents. Many participants regarded inconvenient transportation as the most significant contributor to everyday stress. Those who had no transportation option other than the host family's car felt uneasy whenever they asked hostfamily members for transportation to a place other than school. Occasionally, they gave up on social life with friends altogether, and instead spent large amounts of time in the host homes, which strengthened their feelings of isolation and loss of control over their free time.

\section{Isolation and Romanticization}

Those daily experiences in the United States drove this study's twofold conclusion about characteristics of participants' life experiences: first, the socially isolated young international students spent an excessive number of hours in their own rooms; second, they often described their past experiences in Korea in idealized terms.

A lack of social opportunities fostered a tendency to build relationships exclusively with fellow Koreans. Because of the limited number of Koreans, however, peer activities tended to be infrequent. In addition, their restricted mobility confined them to their host homes. At home, many participants also felt instability because of the transitory nature of their stay and because of the foreign culture. The private room at home frequently served as a refuge from the stresses of interacting with strangers.

Many participants compared their difficult experiences in the United States to their pleasant memories of Korea. Dissatisfied with their living environments, the people they met, and their sociocultural experiences in the United States, they glamorized their past experiences in Korea. This idealization could be attributed mainly to the differences in their personal relationships in the two countries. In the United States, lack of direct parental care and limited peer relationships reduced the social opportunities available to the unaccompanied adolescents. The sharp contrast with their active social lives in Korea led them to romanticize their time there.

Grounded in the findings of the young sojourners’ living contexts, this study set a basic research question:

- How do the transnational online communication practices of young sojourners shape and reflect their transnational lives? 
International Journal of Child, Youth and Family Studies (2015) 6(4.1): 689-708

This question was followed by a series of subquestions probing daily media use and communication practices:

- How do unaccompanied adolescents spend time with media in the United States?

- How do they utilize communications technologies in response to their transnational lives?

- What kinds of media content do they mostly use? Why and how do they use them?

- How do they utilize the Internet for interpersonal communication?

\section{Methods}

\section{Participants}

This research was first conducted in the metro area of Oklahoma City (OKC), because I, as a doctoral student at the University of Oklahoma, was familiar with the Korean community there. OKC is not known as a popular destination for early study abroad: there is no after-school institute for Koreans and no early study abroad agency owned by Koreans. When a series of interviews was conducted in 2010, many participants in OKC complained about the limited number of potential Korean friends in their communities, and their monotonous daily lives caused by the lack of public transportation and the shortage of congenial destinations in the city. Guided by those findings, I conducted the next phase of data collection in a bigger city than OKC in terms of general population, population density, and the size of the Korean community.

Although the Korean-American population in Boston is smaller than in other major cities such as New York and Chicago, Boston is well known in Korea as the most popular destination for early study abroad. Despite the lack of official demographic information, it was easy to find various commercials and information identifying Boston as the most popular site. Unlike the research participants living in OKC, those in Boston had access both to larger Korean communities and to convenient transportation.

The final phase of data collection was conducted in Dallas in late 2010. One of the largest cities in the southwestern region, Dallas has a relatively large Korean community. There were also multiple Korean business centers in the Dallas metro area at the time of this study. While Dallas is larger than Boston in terms of population, there were fewer education-related businesses than in Boston. Since Korean businesses in the Dallas metro area are spread throughout multiple suburban centers like Carrollton and Allen, the living environment for unaccompanied minors was expected to be different from that in Boston.

The Institutional Review Board initially approved the whole research project including this study for the metropolitan area of OKC, followed by approval for Boston and Dallas (IRB no. 12066). In compliance with the approval, all participants were over 18 years old and were either juniors or seniors in high school. Since the first semester of an academic year begins in March in Korea, there are usually some technical problems when Korean students transfer to American high schools. Therefore, Korean high school students usually lose a semester in order to be in line with the American academic calendar. Moreover, many Korean high school students spend around a year practicing English before they transfer to American high schools. For this reason, Korean juniors and seniors are usually older than American students. 
The sampling of this study was purposive. With the help of several key informants in each city, I recruited participants who were not accompanied by their parents, lived with host families, and had been in the United States for over one year. I was also able to recruit additional participants who were introduced by initially recruited participants. A key informant, who was also a Korean high school student in OKC and a friend of my niece, helped recruit participants in OKC. In Boston, a Korean teacher who taught English to Korean students at a private institute introduced eight students to me. A participant in Boston also helped me recruit another two students. In Dallas, a former student of mine introduced two participants, and those two students helped me recruit four more.

Table 1

Demographic Information of Participants

\begin{tabular}{lc}
\hline Category & Number of Participants \\
\hline Current City & 15 (Male: 8, Female: 7) \\
OKC & 10 (Male: 7, Female: 3) \\
Boston & 6 (Male: 4, Female: 2) \\
Dallas & \\
Age & 17 (Male: 11, Female: 6) \\
18 & 14 (Male: 8, Female: 6) \\
19 & 10 (Male: 6, Female: 4) \\
Years in the US & 19 (Male: 13 Female: 6) \\
$1-2$ & 2 (Male: 0, Female: 2) \\
$2-3$ &
\end{tabular}

\section{Data Analysis}

Based on a pilot study with three participants in 2008, I initially developed 23 openended questions in three categories: general questions about the participants, questions regarding the uses of communications technology, and questions regarding everyday communication and interpersonal relationships. Following the methodological guidelines of the grounded theory method, I began data analysis as soon as the first data were collected (Charmaz, 2006). The first data analysis allowed me to add more questions and categories to the interview protocol for the next phases of data collection. Therefore, the next phases of data collection in the three cities were conducted with five categories and a total of 52 questions.

I transcribed interviews verbatim in Korean for data analysis and coded the data by repeatedly reading the fully-transcribed interviews in order to compare interviews and find similarities and differences in the data, which eventually led to finding common themes. The coding process was divided into multiple steps. First, a list of codes was made after reading the transcripts repeatedly. Second, after being compared to one another multiple times, similar and related responses from different participants were inserted in the same column on a workbook in Excel. Third, each code was assigned an inserted response, and only exclusively related responses were left in the same column. Finally, I selected and underlined important comments representing each theme. This process was conducted not only for refining the properties of each theme but also for describing the essential nature of the themes (Thorne, 2000). These underlined 
International Journal of Child, Youth and Family Studies (2015) 6(4.1): 689-708

comments and their corresponding themes were reviewed by a colleague, a native of Korea, at my institution in order to ensure reliability. During the process of data analysis, each participant was assigned a pseudonym.

\section{Findings}

\section{Always Online}

In studying the life experiences of the participants, I found that the socially isolated young international students spent a strikingly large number of hours in their own rooms. A lack of other social opportunities fostered a tendency to build relationships exclusively with fellow Koreans. However, with relatively few other Koreans available, possibilities for peer activities were rather limited. In addition, their restricted mobility tended to confine them to their host homes. At home, many participants also felt instability because of the transitory nature of their stay and because of the foreign culture. The private room at home was felt to be secure from undesired encounters with strangers. The students' isolation in their own rooms set the stage for intensive Internet use. Only four participants occasionally watched television in the living room. Most hours at host homes were devoted to Internet-based activities. Although most participants reported that studying was one of their main activities after school, it was also blurred with Internet use:

I don't know how much I use the Internet. I am just always online. Nothing special done. Search some information. Watch some TV clips. Sometimes chat with friends online. But, I use the Internet all the time when in my room. (Minkee in OKC)

The participants often compared their active social lives in Korea with their monotonous ones in the United States, which led them to romanticize their past in Korea. Their patterns of Internet use apparently reflected this preference.

\section{Transnational Mass Media Use}

Watching "Korean television" in the U.S. In order to comprehend the patterns of media use, it is important to note that the young students did not regard television and the Internet as clearly distinct media. The ongoing convergence of media technologies produces an indifference to the technical specifics of media delivery. Most of the participants who consumed Korean television content through the Internet said "I watch Korean TV" because the content was originally developed for television.

These young adolescents, adroit in the use of the Internet, obtained their viewing material in a variety of ways: some of them paid money for multimedia content, while others illegally downloaded electronic files. They actively shared their downloaded content with their friends using flash drives. Since pirate file-sharing services were frequently shut down by the Korean government, the students actively sought alternative sources from web services based in China and Southeast Asian countries.

However, watching Korean television via the Internet was not a new pattern the students developed in the United States. In Korea, the adolescents spent most of their after-school hours at "cram schools", and rarely had occasion to watch broadcast television. They were already used 
to watching television shows via the Internet, and accustomed to controlling their media consumption with the power to pause, resume, skip, and replay shows at will. Six participants even reported that they had not watched television on a television set in a long time. Therefore, the use of the Internet for consuming Korean media content had already been contextualized in their daily lives, and they simply maintained the old pattern even after relocation.

Table 2

Activities at Host Home and Internet Use

\begin{tabular}{lc}
\hline \multicolumn{1}{c}{ Category } & $\begin{array}{c}\text { Number of } \\
\text { Participants (Percentage) }\end{array}$ \\
\hline *Activites at host home & $30(97 \%)$ \\
Internet surfing & $25(81 \%)$ \\
Consuming Korean media content & $16(52 \%)$ \\
Watching American TV shows via the Internet & $30(97 \%)$ \\
Internet messaging, phone call & $8(26 \%)$ \\
Video (computer) games & $4(13 \%)$ \\
Watching TV in the living room & $28(90 \%)$ \\
Studying & $8(26 \%)$ \\
Talking with host family and housemates & \\
& \\
Default home page of web browser & $15(48 \%)$ \\
Naver, Korea & $6(19 \%)$ \\
Google, USA & $5(16 \%)$ \\
Daum, Korea & $2(6 \%)$ \\
Nate, Korea & $2(6 \%)$ \\
Yahoo, USA & $2(6 \%)$ \\
Blank & \\
\hline
\end{tabular}

Note. The category marked * was counted multiple times.

Many participants (26 out of 31) identified "familiarity" as the reason they watched certain television shows intensively. They said that their habitual watching of those shows could be traced back to their time in Korea. Taewon divulged that he watched most weekend shows while in Korea and continued that practice in the United States. During weekdays in Korea, he did not have enough time to watch television due to his tight school schedule. Many participants also pointed out the importance of Korean sensibility in their media consumption. They were more interested in the love stories, crime scenes, and family conflicts in Korean television dramas than in those of American television. Inpyo said:

When watching Korean reality TV shows, I can feel these shows try to deliver some messages like family value and real friendships. I think they are our common sensibilities. Korean reality shows and comedies are much funnier than those of American. I know it's a bit because of my language. But still I feel the same code. (Inpyo in Boston).

Participants identified the different languages and cultures of the two countries as the main reasons they avoided American sitcoms and shows for teenagers. Since most young participants 
mainly consumed television shows for fun, they wanted to watch those shows mindlessly. However, it was hard for the young sojourners to sufficiently understand the flow of American television shows. Although several participants initially tried to watch American television shows for the purpose of learning English, the motivation did not last long:

I don’t enjoy American TV with no reason. They are just no fun. In the beginning of my American life, I tried to watch American TV shows because all the people told me that they would be helpful for me to improve my English. But, I gradually avoided them. I can easily watch Korean TV shows, which are more fun (Dowon in Dallas).

Watching American television shows with Korean subtitles. Many participants (22 out of 31) also routinely watched American television shows such as Prison Break, Grey's Anatomy, and American Idol. However, they did not rely on television sets in the living room but on electronic files of those shows downloaded onto their own computers in their rooms.

The availability of Korean subtitles and habitual use of the Internet were the main reasons for consuming American television shows available online. According to participants, it was very easy to download American shows with Korean subtitles on the Internet. While they mostly understood American television without Korean subtitles, many preferred subtitled shows. They even downloaded American shows that were imported and broadcast in Korea. Some participants said they continued to consume multiple American shows they had watched before coming to the United States. In this case it was hard to distinguish consuming American shows from consuming Korean ones:

My favorite is Prison Break. I completed season 1 and 2 in Korea and season 3 and 4 in the States. I already got all files of season 5 with Korean subs. I watched American dramas a lot in Korea and I'm still watching most of them here. (Doosik in OKC)

On the other hand, some participants expressed their discomfort with spending time in the living room instead of their own room. Jin, Joon, and Yuna said they did not enjoy watching television with host-family members in living rooms:

I sometimes watched American TV shows like American Idol with my host mom and dad, but I don't feel comfortable with that. They don't pressure me and it is, of course, a relaxed time; nevertheless, I am not comfortable on the couch. They are elder persons and actually not my family members. I feel I must be nice and humble in front of them (Joon in $\mathrm{OKC})$.

Jin had different reason for not liking to watch television shows with host-family members. Her older host parents always watched old-fashioned shows, which were too boring for her. The Christian family also blocked channels she liked, such as MTV. In such circumstances, the young students preferred watching television shows in their rooms on their personal computers.

Keeping updated. Obtaining information from Korea was one of the most common motivations for Internet use. Some participants specifically expressed that these activities prevented them from feeling left behind. Although they admitted that seeking Korea-related information was not directly related to their everyday needs, they insisted that knowing updated information made them feel involved in Korean communities. The strong preference for Korea- 
International Journal of Child, Youth and Family Studies (2015) 6(4.1): 689-708

related information was also reflected in their responses to the question, "What is the home page of your Web browser?”. Many students set Korean portal services as their default home pages (Table 2).

One of the popular targets of information seeking was gossip about Korean entertainers. There were abundant news items and many stories about Korean celebrities on the Internet, especially on blogs, online newspapers, and various Internet forums. Jin, one of the most active participants, searched for information on her favorite Korean actor:

I'm a big fan of an actor, Jang Geun Seok. I search for information about him over the Internet. Do you know Tel-Zone service at Daum? Tel-Zone has all the information I seek: entertainers' photos and gossip. New information is updated every moment. I feel I need to follow it. Visiting Tel-Zone is part of my daily routine (Jin in OKC).

Many young participants paid attention exclusively to Korean popular stars rather than American celebrities. According to Joon, multimedia content featuring Korean celebrities was helpful for catching up with new Korean cultural and fashion trends. Sungil actively sought information related to Korean television shows that he watched because information about newly-aired shows was a good resource for his everyday conversations with Korean friends.

The young sojourners actively sought newly updated information about and from Korea. Although these activities clearly demonstrated their need for keeping up with their long-time interest in events occurring in Korea, as some participants indicated, the information from Korea also helped them forget about feeling separated from familiar people and experiences. Some participants also believed that obtaining Korea-related information and consuming Korean media would help them maintain healthy relationships with Korean friends.

Transnational interpersonal communication. Instant and constant connectivity is a unique characteristic of the Internet that led the unaccompanied young sojourners to use technology intensively in their long-distance communication with family members and peers in Korea. Participants in this study listed several different means of interpersonal communication on the Internet. Some participants communicated exclusively with Korean people in both Korea and the United States.

Media consumption for peer relationships. By repeatedly reading transcribed interviews and comparing multiple categories of findings, I found that one of the main purposes for participants' media consumption was to conduct interpersonal communication across borders. The Internet was the main communication channel for the young sojourners not only to continue their consumption of Korean media, but also to interact with peers in Korea. However, conversations with these peers ran the risk of being limited to rote topics or casual greetings. Therefore, many participants made special efforts to develop subjects they could talk about with friends in Korea. New episodes of a television show provided good material to help them initiate or continue conversations with their old friends in Korea. Some participants identified televisionrelated topics as the most popular sources of their daily conversations with their old friends via the Internet:

Television is a kind of connection with my old buddies in Korea. Though we talk with each other frequently, I sometimes feel that we don’t have many things to chat about. 
International Journal of Child, Youth and Family Studies (2015) 6(4.1): 689-708

After talking about boyfriends briefly, television shows and stars became the only topics we can share. Because I watch Korean TV shows almost real time, I can share my opinions, feelings, and gossips with my friends in Korea (Soo in OKC).

Jimin actively used Korean television shows as topics of conversation with her peers in Korea. She employed the phrase "develop topics" in order to stress her efforts to maintain old relationships by using television-related topics. In Jongsoo’s case, English Premier League Soccer was a means of maintaining his friendships with friends in Korea. He watched English soccer matches every Saturday morning during the soccer season. He learned about the league and watched highlights of matches via streamed Webcasts from Daum, one of the largest portal websites in Korea. Advanced Internet technologies made it possible for the students to constantly and instantly contact their Korean peers.

Transnational peer communications. Although the young international students often felt that their social life dramatically decreased after arriving in the United States, they actively tried to build and maintain online social relationships. With the exceptions of Song, Han, and Young, all participants in this study maintained close online relationships with Korean friends by using Cyworld, a Korea-based social networking site. Soo pointed out that various kinds of multimedia content, including photos and pictorial journals she and her friends posted on Cyworld, helped her share everyday experiences and memories with long-distance friends.

Use of Facebook was much less frequent, even when participants did have accounts on that service. Some participants reported that the different meanings of friend and friendships in the United States were reflected on Facebook, which hindered them from becoming active on the site:

Most friends added on my Facebook are not real friends. Some of them never even greet me at school. They just "collect” friends. I think it is their culture; for example, they are kind to me at the beginning of a school year, but then they never greet me.... But on my Cyworld, I have many close friends both in Korea and the U.S. I feel I connected with them when using Cyworld. We are also good friends at school or in my town. Korean friends on my Cyworld share many interesting things that I can easily enjoy. Their postings make me miss them a lot (Yuna in Boston).

Since the Cyworld service is interlocked with NateOn, Korea's largest instant messaging (IM) service, using both services is common, allowing the international students to communicate easily in real time with people in Korea. For example, Heeseon used NateOn as her main route to reach Korean friends. If one of her friends updated a new activity on Cyworld, NateOn notified her about it. Therefore, NateOn was not only a messenger delivering her friends' messages to her but also a tool that kept her informed about the everyday lives of her old friends. She found it an effective means to share daily experiences.

Without exception, all participants could maintain long-distance peer relationships via the Internet. Although a few participants felt that they and their old friends had drifted apart somewhat, most were able to maintain their intimate relationships with old friends by frequent communication. In their everyday lives at host homes and schools, they had few or no dynamic social relationships. But in their private rooms, they became active social beings interacting with old friends through advanced communications technologies. Their peer relationships across 
International Journal of Child, Youth and Family Studies (2015) 6(4.1): 689-708

borders went beyond simply maintaining contacts; rather, the students tried to maintain stable peer networks by sharing their daily lives and spending time to understand their friends' lives in Korea.

Table 3

Interpersonal Communication via the Internet

\begin{tabular}{lc}
\hline \multicolumn{1}{c}{ Category } & Number of Participants (Percentage) \\
\hline Rate of communications with parents & $2(6 \%)$ \\
Once a month & $7(23 \%)$ \\
Once a week & $14(45 \%)$ \\
$2-4$ times a week & $8(26 \%)$ \\
5 times or more a week & \\
& With parents/with friends in Korea \\
*Means of communication & $21 / 24(68 \% / 77 \%)$ \\
Email & $12 / 26(39 \% / 84 \%)$ \\
Internet messaging & $5 / 1(16 \% / 3 \%)$ \\
International phone card & $19 / 3(61 \% / 10 \%)$ \\
070 Internet phone & $15 / 27(48 \% / 87 \%)$ \\
Social network sites & \\
& \\
*eer activities on the Internet & $11(35 \%)$ \\
With Non-Koreans & $21(68 \%)$ \\
With Koreans in the United States & $27(87 \%)$ \\
With Koreans in Korea &
\end{tabular}

Note. Categories marked * were counted multiple times.

Transnational family communications. While separated from family members, the unaccompanied adolescents tended to maintain close ties of communication with their parents. Most participants, with the two exceptions of Han and Song, routinely shared their daily experiences with their parents and consulted them about study, personal relationships with host families and friends, and future plans. However, many participants expressed that these frequent exchanges were not just utilitarian but reflected their closeness to their parents. Many who experienced limited peer relationships in the United States regarded their parents as their best friends:

My mom calls me almost every day. I also call her occasionally. So we sometimes call each other three times a day. Even if we talk a lot, I still have lots of things to tell her. She wants to know what happened to me every day. I also have many things to talk about and ask my mom. She is kinda my best friend now (Soo in OKC).

IM and the 070 Internet phone (an Internet phone service based in Korea) were their main communication channels for reaching their parents, although many participants also used email. The 070 Internet phone service became popular in late 2008 when a carrier marketed it as a free service among 070 subscribers, regardless of their location. When using the 070 Internet phone, a user does not have to enter the international area code or long-distance pass code that most international phone card services require. The students were able to keep 070 phone devices in 
their own rooms, and so did not need to share telephones with host-family members. Many participants agreed that the new technology increased their frequency of communication with their parents so much that it made them feel closer to their parents. Since they could also send text messages in Korean to friends and parents by using the 070 phone, some noted that it was as though they were in Korea themselves, and that this psychological closeness helped to allay their daily stresses.

Since many participants actively communicated with their parents, I asked a related question about changes in intimacy with their parents after the participants arrived in the United States. However, no participant reported such a change. Participants who communicated with parents extensively also had a close relationship with their parents when they were in Korea, and the converse was also true: most who communicated less also reported less intimate communication with their parents even when in Korea. Neither physical distance from parents nor new communications technologies affected the quality of family relationships.

\section{Summary of Demographic Findings}

As indicated in the methods section, the present study recruited participants in three different cities. While individual differences existed in the results from each city, no strong pattern of variation emerged in the consumption of Korean media and transnational communication with people in Korea by participants. In Boston, four participants reported that it was easy for them to make new Korean friends because of the large size of the community of Korean early abroad students. However, none maintained stable relationships with new Korean friends made in Boston. It was only with Korean friends in Korea that they created stable networks of peer relationships. Except for the few who made a special effort to avoid heavy use of the Internet, participants in the three cities spent a large amount of time with the Internet in order to consume Korean media content and to communicate with people in Korea.

While there was no a significant difference between male and female participants in their consumption of Korean media content, female participants tended to communicate more frequently with parents than male participants did. Three female participants spoke on the phone with their parents every day. On the contrary, two male participants rarely communicated with their parents over the phone. Many other male participants did not call their parents as often as most female participants did. Although there were gender differences in the frequency of communication with parents, most participants reported that they did not feel a barrier to communication with family members. Since they could use many different communications technologies, they could easily share the issues, needs, and concerns of their everyday lives with their family members. There was no evidence that male participants intentionally avoided phone calls with parents. When asked why they did not often speak to their parents on the phone, many male participants answered that they rarely called their parents even before they came to the United States. Thus, this was another example showing that their communication practices did not change dramatically after they crossed the border.

\section{Discussion}

"I want to go back home to Korea” was one of the most frequent statements made by participants throughout the interviews. Boredom and loneliness in the United States were the two most common reasons for their homesickness. The students tended to think that these feelings 
International Journal of Child, Youth and Family Studies (2015) 6(4.1): 689-708

were the product of their isolated lives at host homes and limited peer relationships. The unaccompanied adolescents spent most of their time outside school in their own rooms at host homes.

Since Internet use was not a goal in itself for the participants, many of them had difficulty accounting for their Internet usage in detail. However, their frequent use of the Internet could suggest that they were grounded more in communities in Korea than in the United States. The majority of participants still used Korean websites as their informational hubs, consumed media content through Korean Web services, and maintained existing family and peer relationships in Korea. Although living in the United States and attending American high schools, their afterschool hours were filled with activities related to their old communities in Korea, which were mediated through the Internet. Like the young Eastern European migrants in the United Kingdom that Metyková (2010) discussed in her study, the unaccompanied Korean adolescents also maintained their routine patterns of media consumption and interpersonal communication, which were formed before they came to the United States.

The findings of the study suggest that there were three important aspects to the unaccompanied adolescents' transnational media consumption and interpersonal communication. First, technological availability and literacy were important conditions for transnational media consumption. Participants in this study were adept at accessing media sources by using their own laptops. They also actively shared information regarding Korean media content with peers in both Korea and the United States. These low-cost and easy-to-use technologies also helped them keep in touch with people they felt more attached to than those in the United States.

Second, cultural sensibilities and emotional attachment were crucial reasons for their consumption of Korean media and involvement in communities in Korea. As presented in the study of unaccompanied adolescents' life experiences (Kim, 2014), they tended to romanticize past experiences and people in Korea partly because of their limited social relationships and unsatisfactory life experiences in the United States. Their strong preferences for Korean media content could also be further evidence of their romanticization of Korea-related things. Advanced communications technologies made it possible for the adolescents to communicate with their parents in Korea to any desired degree. Some participants regarded this as a vital means of maintaining psychological health in their transnational lives in the United States.

Third, both their consumption of Korean media and interpersonal communication with people in Korea can be explained by their desire to remain involved in peer communities based in Korea. Distanced from their old friends in Korea, and unable to share other types of experiences with them, the young sojourners often used their common viewing of Korean television shows as material for social exchanges. The adolescents also utilized multiple Internet technologies that kept them informed about their friends' everyday lives in Korea. These shared experiences facilitated by the Internet became an important means of maintaining their social lives.

\section{Concluding Remarks}

While the abovementioned practices represent interesting transnational scenes in relation to new communications technologies and migrant lives, it is also important to point out that these communication practices were not completely new for the adolescents. Rather, as many 
participants reported, they maintained their habitual patterns of media consumption, kept their cultural tastes, and stayed in touch with people in Korea, practices already built into their daily lives in Korea. In other words, their communication practices in the United States were not solely caused by their life experiences in the United States. But it is would be mistaken to conclude that their transnational communication practices were solely the result of the development and diffusion of new technologies. Rather, their media use and interpersonal communication via the Internet had been contextualized in complex relation to sociocultural environments and their daily lives both in Korea and the United States.

This study did not predetermine a direction of cause and effect, such as "migrants' life experiences might lead to certain communication practices" or "transnational communication transforms migrants' life experiences.” Instead, it initially posited that a comprehensive understanding of the contexts of the participants' lives was key to an understanding of their communication practices. It could not be denied that limited personal relationships was one of the main problems forcing the students to be isolated in their private spaces. However, their isolation was not solely caused by the conditions of their lives but also by their choice to maintain habitual use of the Internet. The unaccompanied Korean adolescents' limited personal relationships and social activities in the United States were reciprocally strengthened by the excessive use of the Internet and exclusive communication with Koreans.

On the surface, the unaccompanied Korean adolescents began their transnational lives after arriving in the United States. However, their actual transnational lives had already begun in Korea. On the one hand, as reviewed earlier, their study abroad was a response to global political economic relationships; on the other, the students had already been active transnational media users, flexibly adopting advanced communications technologies.

The international students attended American schools in order to improve their English skills and enter American colleges, both of which are regarded as important symbolic capital. In spite of psychological burdens imposed by misunderstandings, uncomfortable relationships with people, and uncertain futures, they strove to achieve their goals in school. After long school hours, they could have isolated, but less stressful, time in their private rooms, with tools to let them return to their comfortable neighborhoods. That is to say, they simultaneously or alternately experienced real, yet strange, neighborhoods, and virtual, yet familiar, neighborhoods. According to Appadurai (1996), neighborhoods are contexts within which human behaviors are set. The young sojourners resided flexibly in both neighborhoods, and their living contexts were not exclusively shaped by certain neighborhoods. Instead, their lives existed between the two neighborhoods. The old and the new were then integrated to create new contexts in their transnational lives. 
International Journal of Child, Youth and Family Studies (2015) 6(4.1): 689-708

\section{References}

Ahn, S. (2011). Global citizenship and global solidarity through study abroad: An exploratory case study of South Korean students. Journal of International Social Studies, 1, 21-34.

Appadurai, A. (1996). Modernity at large: Cultural dimensions of globalization. Minneapolis: University of Minnesota Press.

Bacigalupe, G., \& Camara, M. (2012). Transnational families and social technologies: Reassessing immigration psychology. Journal of Ethnic and Migration Studies, 38(9), 1425-1438. http://dx.doi.org/10.1080/1369183x.2012.698211

Charmaz, K. (2006). Constructing grounded theory: A practical guide through qualitative analysis. Thousand Oaks, CA: Sage.

Christiansen, C. C. (2004). News media consumption among immigrants in Europe: The relevance of diaspora. Ethnicities, 4(2), 185-207. http://dx.doi.org/10.1177/1468796804042603

Collins, F. L. (2009). Connecting 'home' with 'here': Personal homepages in everyday transnational lives. Journal of Ethnic and Migration Studies, 35(6), 839-859. http://dx.doi.org/10.1080/13691830902957668

Kang, J., \& Abelmann, N. (2011). The domestication of South Korean pre-college study abroad in the first decade of the millennium. Journal of Korean Studies, 16(1), 89-118. http://dx.doi.org/10.1353/jks.2011.0001

Kang, 'I'. (2012). Gendered media, changing intimacy: Internet-mediated transnational communication in the family sphere. Media, Culture \& Society, 34(2), 146-161. http://dx.doi.org/10.1177/0163443711430755

Kang, Y. (2013). Global citizens in the making: Child-centred multimedia ethnographic research on South Korean student migrants in Singapore. Ethnography, 14, 1-22. http://dx.doi.org/10.1177/1466138113491673

Kim, H. (2005, May). Jogi yoohak: Gookmin uisik gwa siltae. [Early study abroad: Citizen’s perceptions and realities]. In the $26^{\text {th }}$ KEDI Educational Policy Forum, Seoul, Korea.

Kim, T. S. (2014). A qualitative inquiry into the life experiences of unaccompanied Korean adolescents in the United States. The Qualitative Report, 19(40), 1-22.

Koo, H. (2007). The changing faces of inequlity in South Korea in the age of globalization. Korean Studies, 31, 1-18. http://dx.doi.org/10.1353/ks.2008.0018

Korean Educational Development Institute (KEDI ). (2012). Jiyukbyul jogiyuhaksaeng soo [Number of early study abroad students by region] Retrieved March 4, 2012, from http://edpolicy.kedi.re.kr

Korean Statistical Information Service (KOSIS). (2012). Urinara cho-jung-go haksaengui sahgyoyuk hyunhwang [The status of private education of Korean precollege students]. Retrieved July 8, 2012 from http://www.index.go.kr

Kuo, B. C. H., \& Roysircar, G. (2006). An exploratory study of cross-cultural adaptation of adolescent Taiwanese unaccompanied sojourners in Canada. International Journal of Intercultural relations, 30, 159-183. http://dx.doi.org/10.1016/j.ijintrel.2005.07.007 
International Journal of Child, Youth and Family Studies (2015) 6(4.1): 689-708

Lin, W. Y., Song, H., \& Ball-Rokeach, S. (2010). Localizing the global: Exploring the transnational ties that bind in new immigrant communities. Journal of Communication, 60(2), 205-229. http://dx.doi.org/10.1111/j.1460-2466.2010.01480.x

Mayer, V. (2003). Living telenovelas/telenovelizing life: Mexican American girls' identities and transnational telenovelas. Journal of Communication, 53(3), 479-495. http://dx.doi.org/10.1093/joc/53.3.479

Metyková, M. (2010). Only a mouse click away from home: Transnational practices of Eastern European migrants in the United Kingdom. Social Identities, 16, 325-338 http://dx.doi.org/10.1080/13504630.2010.482418

Miller, T. (2007). Cultural citizenship: Cosmopolitanism, consumerism, and television in a neoliberal age. Philadelphia: Temple University Press.

Moon, S. (2011). Expectation and reality: Korean sojourner families in the UK. Language and education, 25(2), 163-176. http://dx.doi.org/10.1080/09500782.2011.554986

Ong, A. (1999). Flexible citizenship: The cultural logics of transnationality. Durham, NC: Duke University Press.

Palfrey, J., \& Gasser, U. (2008) Born digital: Understanding the first generation of digital natives. New York: Basic Books.

Park, H., Byun, S. Y., \& Kim, K. K. (2011). Parental involvement and students' cognitive outcomes in Korea focusing on private tutoring. Sociology of Education, 84(1), 3-22. http://dx.doi.org/10.1177/0038040710392719

Park, J. K. (2009). 'English fever' in South Korea: Its history and symptoms. English Today, 25, 50-57. http://dx.doi.org/10.1017/s026607840900008x

Park, S. J., \& Abelmann, N. (2004). Class and cosmopolitan striving: Mothers' management of English education in South Korea. Anthropological Quarterly, 77(4), 645-672. http://dx.doi.org/10.1353/anq.2004.0063

Popadiuk, N. E. (2010). Asian international student transition to high school in Canada. The Qualitative Report, 15, 1523-1548.

Portes, A. (2001) Introduction: The debates and significance of immigrant transnationalism. Global Networks, 1(3), 181-94. http://dx.doi.org/10.1111/1471-0374.00012

Ryu, I. (2008). Go-So-Young, power suchiro ipjeung doeda [Numbers prove the power of GoSo-Young]. The Hankyoreh. Retrieved January 13, 2012, from http://www.hani.co.kr

Shin, H. (2013). Ambivalent calculations in Toronto: Negotiating the meaning of success among early study abroad high school students. Asian and Pacific Migration Journal, 22(4), 527-546. http://dx.doi.org/10.1177/011719681302200404

Sun, W. (2005). Media and the Chinese diaspora: Community, consumption, and transnational imagination. Journal of Chinese Overseas, 1(1), 65-86. http://dx.doi.org/10.1353/jco.2007.0007

Tartakovsky, E. (2007). The psychological well-being of unaccompanied minors: A longitudinal study of adolescents immigrating from Russia and Ukraine to Israel without parents. Journal of Research on Adolescence, 19, 177-204. http://dx.doi.org/10.1111/j.1532-7795.2009.00589.x 
International Journal of Child, Youth and Family Studies (2015) 6(4.1): 689-708

Thorne, S. (2000). Data analysis in qualitative research. Evidence-Based Nursing, 3, 68-70. http://dx.doi.org/10.1136/ebn.3.3.68

Vertovec, S. (2004) Cheap calls: The social glue of migrant transnationalism. Global networks, 4(2), 219-224. http://dx.doi.org/10.1111/j.1471-0374.2004.00088.x

Wang, Y, \& Quan, X. (2013). Does ethnic Internet use deter or promote cross-cultural adaptation? Journal of Media and Communication Studies, 5(7), 78-87.

Wilding, R. (2006). 'Virtual'intimacies? Families communicating across transnational contexts. Global networks, 6(2), 125-142. http://dx.doi.org/10.1111/j.1471-0374.2006.00137.x

Ye, J. (2005). Acculturative stress and use of the Internet among East Asian international students in the United States. CyberPsychology \& Behavior, 8(2), 154-161. http://dx.doi.org/10.1089/cpb.2005.8.154

Yin, H. (2013). Chinese-language cyberspace, homeland media and ethnic media: A contested space for being Chinese. New Media \& Society. Advance online publication. doi: $\underline{10.1177 / 1461444813505363}$

Ying, Y. (2001). Migration and cultural orientation: An empirical test of the psychoanalytic theory in Chinese Americans. Journal of Applied Psychoanalytic Studies, 3, 409-430.

Yoon, K. (2006). The making of neo-Confucian cyberkids: Representations of young mobile phone users in South Korea, New Media \& Society, 8, 753-771.

http://dx.doi.org/10.1177/1461444806067587 